\title{
Preparation of Sintered $\beta$-Tricalcium Phosphate from Dehydrated Amorphous Calcium Phosphate
}

\author{
Takao UMEGAKI, Mitsuo SHIOMI* and Takafumi KANAZAWA \\ Department of Industrial Chemistry, Faculty of Technology, Tokyo Metropolitan University \\ 1-1, Fukasawa 2-chome, Setagaya-ku, Tokyo 158 \\ * Now with Toyo Soda Co., Ltd.
}

\section{脱水非晶質リン酸カルシウムからの $\beta-\mathrm{Ca}_{3}\left(\mathrm{PO}_{4}\right)_{2}$ 焼結体の調製}

\author{
梅垣高士・塩見光生*・金澤孝文 \\ ( $\begin{gathered}\text { 東京都立大学 工学部 工業化学科 } \\ \text { *現在 } \text { 東洋曹達工業 }(\text { 株) }\end{gathered}$
}

\begin{abstract}
Amorphous calcium phosphate, after thermally dehydrated, was used as a starting material for preparation of sintered $\beta$-Ca $a_{3}$ $\left(\mathrm{PO}_{4}\right)_{2}$. Specific surface area and pore size distribution of the dehydrated powders were examined from the adsorption isotherms in order to clarify the relation between the powder properties of dehydrated samples and the sintering process. Sintered $\beta$ - $\mathrm{Ca}_{3}$ $\left(\mathrm{PO}_{4}\right)_{2}$ with more than $90 \%$ of theoretical density was prepared from crystalline $\alpha$-tricalcium phosphate which was obtained at $700^{\circ} \mathrm{C}$, while dense bodies were formed by hot pressing at $24 \mathrm{MPa}$ and $1100^{\circ} \mathrm{C}$ for 30 min from the starting powders calcined at low temperature. The hindrance of densification by mesopores $(20-200 \AA)$ in the dehydrated powder particles might be eliminated by the thermal crystallization and the hot pressing.

[Received February 13, 1987; Accepted April 21, 1987]
\end{abstract}

Key-words : Amorphous calcium phosphate, Sintering, Hot pressing, $\beta$-tricalcium phosphate, Pore size distribution, Mesopore

\section{Introduction}

Amorphous calcium phosphate (ACP), known as a precursor of hydroxyapatite, gives a halo pattern in X-ray powder diffraction. Samples of ACP obtained by freeze-drying contain $15-20$ wt $\%$ of water.

In the preceding papers, ${ }^{11,2)}$ it was reported that the molar ratio $\mathrm{Ca} / \mathrm{P}$ in most $\mathrm{ACP}$ was close to 1.5 and that $\alpha$ - or $\beta-\mathrm{Ca}_{3}\left(\mathrm{PO}_{4}\right)_{2}(\alpha$-or $\beta$-TCP $)$ was obtained by thermal crystallization of ACP. On the other hand, ACP remained amorphous up to $600^{\circ}-700^{\circ} \mathrm{C}$ probably because of the presence of a small amount of water in the interstitials of calcium phosphate particles in ACP. ${ }^{3)}$

Below the crystallization temperature dehydrated ACP possessed a large specific surface area $\left(40-100 \mathrm{~m}^{2} / \mathrm{g}\right)$ and $\alpha$ - or $\beta$-TCP obtained from ACP consisted of fine powder crystals (above $10 \mathrm{~m}^{2} / \mathrm{g}$ ) after heat-treatment at about $700^{\circ} \mathrm{C} .{ }^{4)}$

Many attempts were carried out in order to use sintered TCP as one of the bioabsorbable materials. Hydroxyapatite precipitates in alkaline solution and $\mathrm{CaHPO}_{4} \cdot 2 \mathrm{H}_{2} \mathrm{O}$ and $\mathrm{Ca}\left(\mathrm{H}_{2} \mathrm{PO}_{4}\right)_{2} \cdot 2 \mathrm{H}_{2} \mathrm{O}$ are prepared in neutral and acidic solutions, respectively. However, no direct synthesis for TCP in solution has been found yet. Moreover, it is impossible that no fine crystalline TCP powder suitable for sintering can be obtained by the solid-state reaction between $\mathrm{CaHPO}_{4}$ or $\mathrm{Ca}_{2} \mathrm{P}_{2} \mathrm{O}_{7}$ and calcium salts. Therefore, sulfate ion was needed to be introduced into starting materials on preparation of sintered $\beta$-TCP. ${ }^{5)}$

The present paper deals with studies on the possibility for the production of pure $\beta$-TCP ceramics from dehydrated ACP and the discussion about the relation between the preparative conditions for sintered $\beta$-TCP and the powder properties of dehydrated ACP.

The effects of residual water molecules in ACP was also examined.

\section{Experimental}

2. 1 Preparation of amorphous calcium phosphate

The preparative conditions for ACP were described in the preceding papers. Those conditions were slightly altered so that a single phase of TCP was crystallized on heat-treatment of ACP. Table 1 shows the conditions adopted in the present work.

\section{2 Sintering conditions}

The powders of ACP were dehydrated in air, being kept at a certain temperature for $1 \mathrm{~h}$. The calcined $\mathrm{ACP}$ was examined by $\mathrm{X}$-ray diffraction and IR absorption. 
Table 1. Preparative conditions for amorphous calcium phosphate.

\begin{tabular}{|c|c|c|}
\hline Starting solutions & & \\
\hline $\mathrm{Ca}\left(\mathrm{NO}_{3}\right)=$ & $0.2 \mathrm{~mol} / 1 \quad 150 \mathrm{ml}$ & $\mathrm{pH}=10.0$ \\
\hline$\left.\left(\mathrm{NH}_{4}\right)\right)_{2} \mathrm{HPO}_{4}$ & $0.2 \mathrm{~mol} / 1 \quad 100 \mathrm{ml}$ & $\mathrm{pH}=10.0$ \\
\hline Solution for pH adjustment & $\mathrm{NH}_{\mathbf{3}}$ water & \\
\hline Freeze-drying & $12 \mathrm{hr}$ & \\
\hline
\end{tabular}

The disks $(13 \mathrm{~mm} \phi \times$ ca. $2 \mathrm{~mm})$ for sintering were prepared by uniaxial pressing at $210 \mathrm{MPa}$ for $1 \mathrm{~min}$ at room temperature. The sintering of the samples so obtained was carried out in air or under reduced pressure. Some of the sintered bodies of $\beta$-TCP were also obtained by hot pressing.

The relative density of sintered body was calculated from the bulk density in comparison with the value $\left(D_{\mathbf{x}}=3.07\right)$ of $\mathrm{Mg}$-free whitlockite obtained from X-ray diffraction data. ${ }^{6)}$

2. 3 Powder properties of dehydrated amorphous calcium phosphate and thermally crystallized tricalcium phosphate

Specific surface area in most of the heattreated calcium phosphates was measured by the BET method (liquid nitrogen adsorption). The $V-t$ plots and pore size distribution were also obtained from adsorption and desorption isotherms according to the method by Lippens and de Boer ${ }^{7)}$ and the calculation by Cranston and Inkley, ${ }^{8)}$ respectively.

\section{4 SEM observation}

Dehydrated ACP powder and the surface of sintered bodies were observed by SEM (JEOL JSM-T 20). The surface of sintered body was polished with diamond paste (about $1 \mu \mathrm{m}$ ) and etched thermally at $1000^{\circ} \mathrm{C}$ for $20 \mathrm{~min}$.

\section{Results and discussion}

\subsection{Preparative conditions for amorphous} calcium phosphate

As reported previously, ${ }^{2)} \mathrm{CaHPO}_{4} \cdot 2 \mathrm{H}_{2} \mathrm{O}$ precipitated from the mixture of concentrated alkaline $\mathrm{Ca}^{2+}$ and $\mathrm{PO}_{4}^{3-}$ solutions. Pyrophosphates formed in thermally crystallized TCP when ACP contained the hydrogen phosphates.

From the experimental results about the changes in $\mathrm{Ca} / \mathrm{P}$ ratio with initial $\mathrm{pH}$ and concentrations of starting solutions of calcium and phosphate, it was concluded that pure TCP was obtained from ACP which precipitated from the mixture of low $\mathrm{Ca}^{2+}$ and $\mathrm{PO}_{4}^{3-}$ contents (less than $0.2 \mathrm{~mol} / \mathrm{l})$ and high $\mathrm{pH}(\mathrm{pH}=9-10)$.

3. 2 Powder properties of dehydrated amorphous calcium phosphate

The phases appearing in dehydrated ACP and the change in specific surface area of heat-treated
Table 2. Phase appearing in calcined amorphous calcium phosphate.

\begin{tabular}{cl}
\hline Calcination temp. ( $\left.{ }^{\circ} \mathrm{C}\right)$ & \multicolumn{1}{c}{ Phase } \\
\hline$\sim 700$ & amorphous \\
$700 \sim 800$ & $\alpha$-TCP \\
$800 \sim 900$ & $\alpha-\& \beta-\mathrm{TCP}$ \\
\hline
\end{tabular}

Table 3. Change in specific surface area of calcined amorphous calcium phosphate.

\begin{tabular}{|c|c|c|}
\hline Calcination temp. ( $\left.{ }^{\circ} \mathrm{C}\right)$ & Phase & Surface area $\left(\mathrm{m}^{2} / \mathrm{g}\right)$ \\
\hline 200 & amorphous & 45.8 \\
\hline 500 & amorphous & 40.3 \\
\hline 700 & $\alpha-\mathrm{TCP}$ & 17.0 \\
\hline
\end{tabular}

samples are shown in Tables 2 and 3.

Metastable TCP of high-temperature form consisting of fine crystalline particles was obtained by thermal crystallization of ACP. The outline of thermal change of ACP agreed with that of the preceding papers. ${ }^{1), 2}$ )

Figures 1 and 2 show the $V-t$ plots obtained from adsorption isotherms for dehydrated samples and thermally crystallized TCP, and the pore size distribution curves for the same three samples described above, respectively.

The deviation of the $t$-plots from the dashed lines in Fig. 1 indicated the presence of micropore (smaller than $20 \AA$ ) and mesopore $(20-200 \AA)$ in the heat-treated samples.

Assuming that the multilayer of physisorbed

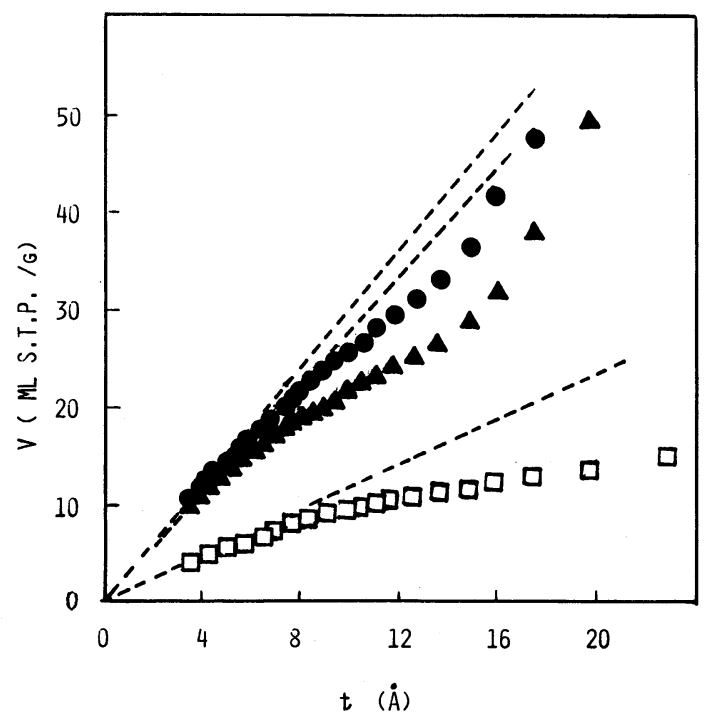

Fig. 1. The $V-t$ plots for dehydrated powder of amorphous calcium phosphate and $\alpha$-tricalcium phosphate obtained by thermal crystallization.

: ACP dehydrated at $200^{\circ} \mathrm{C}, \triangle$ : ACP dehydrated at $500^{\circ} \mathrm{C}, \square: \mathrm{TCP}$ obtained at $700^{\circ} \mathrm{C}$ 


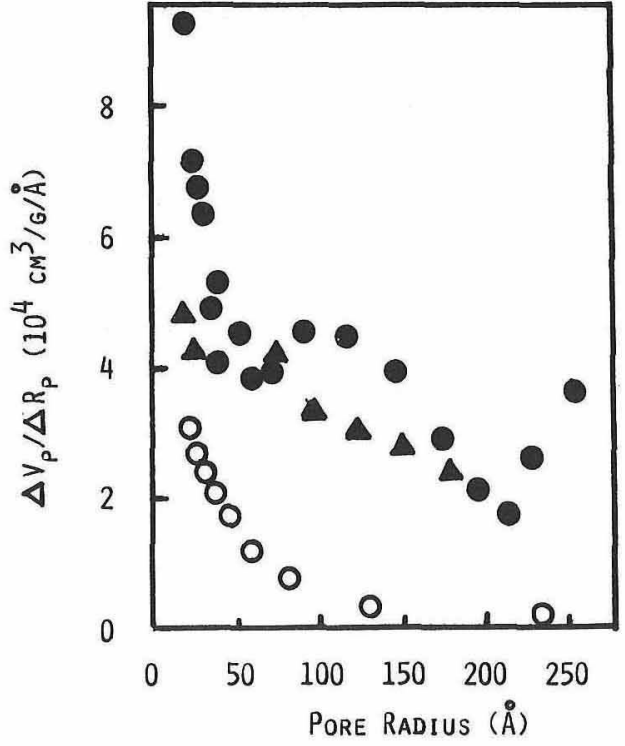

Fig. 2. The pore size distribution for dehydrated powders of amorphous calcium phosphate and $\alpha$-tricalcium phosphate obtained by thermal crystallization.

: ACP dehydrated at $200^{\circ} \mathrm{C}, \triangle$ : ACP dehydrated at $500^{\circ} \mathrm{C}, \mathrm{O}: \mathrm{TCP}$ obtained at $700^{\circ} \mathrm{C}$

nitrogen form unhindered on all parts of the surface, the $V-t$ plot might be one straight line represented by the dashed line.

Concerning the dehydrated and amorphous samples in Fig. 1, at a larger $t$ value in thickness of the multimolecular layer the slopes started to increase and the $t$ plot curves crossed the dashed lines. At larger thickness of adsorption.layer corresponding to higher relative pressure, capillary condensation was considered to occur in the mesopores of 20 to $200 \AA$ in the dehydrated ACP.

In Fig. 2 the high values of $\Delta V_{\mathrm{p}} / \Delta R_{\mathrm{p}}$ representing the frequency of respective pore radius in the range of 100 to $250 \AA$ also suggested the presence of mesopore in the amorphous samples. (a)

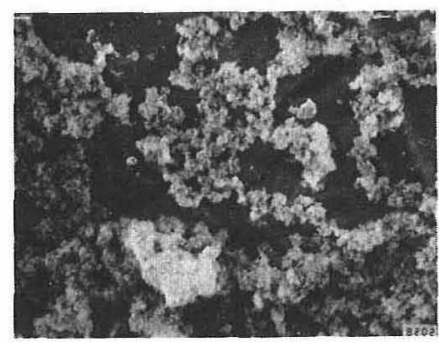

(b)
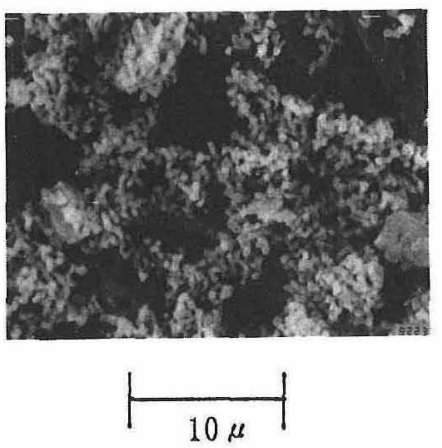

The $V-t$ plot for thermally crystallized TCP indicated that the mesopore disappeared but the micropore still remained. The presence of the slit-shaped pores in all of the calcined samples was recognized by the slope decrease at a thickness of about $20 \AA$. As shown in Fig. 2, the high frequency parts of pore radius in the micropore range were found in the crystallized TCP.

Probably, the disappearance of mesopores and thermal crystallization occurred almost at the same time. However, the micropores still existed after formation of TCP. It was concluded that the dehydrated but amorphous samples had both micropores and mesopores while thermally crystallized TCP possessed only micropores. These findings from the pore distribution curves and those from the $V-t$ plots agreed with one another.

. Figure 3 shows the SEM photographs of calcined ACP. After crystallization the chain-like structure was observed. The morphological change of the powder particles with calcination temperature suggested the pore structure change and the grain growth during the pretreatment of sintering.

3.3 Preparative conditions for sintered $\beta$ tricalcium phosphate

Table 4 shows the relation between sintering temperature and the phase appearing during the sintering process. Sintering should be carried out

Table 4. Phase of sintered body.

\begin{tabular}{|c|c|c|}
\hline $\begin{array}{l}\text { Sintering temp. } \\
\left.\text { ( }{ }^{\circ}\right)\end{array}$ & $\begin{array}{c}\text { Calcination temp. } \\
500^{\circ} \mathrm{C}\end{array}$ & $\begin{array}{c}\text { before sintering } \\
700^{\circ} \mathrm{C}\end{array}$ \\
\hline 550 & amorphous & $\alpha-\mathrm{TCP}$ \\
\hline 660 & amorphous & $\alpha-\mathrm{TCP}$ \\
\hline 820 & $\alpha-\mathrm{TCP}$ & $\alpha-T C P$ \\
\hline 900 & $\alpha-\& \beta-\mathrm{TCP}$ & $\beta-\mathrm{TCP}$ \\
\hline 990 & $\beta-\mathrm{TCP}$ & $\beta-\mathrm{TCP}$ \\
\hline
\end{tabular}

(c)

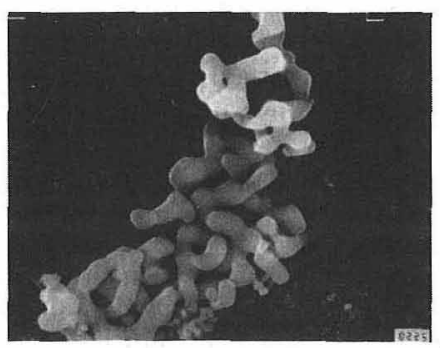

Fig. 3. Scanning electron micrographs of dehydrated amorphous calcium phosphate and thermally crystallized $\alpha$-tricalcium phosphate.

(a) ACP dehydrated at $200^{\circ} \mathrm{C}$, (b) ACP dehydrated at $500^{\circ} \mathrm{C}$, (c) $\mathrm{TCP}$ obtained at $700^{\circ} \mathrm{C}$ 


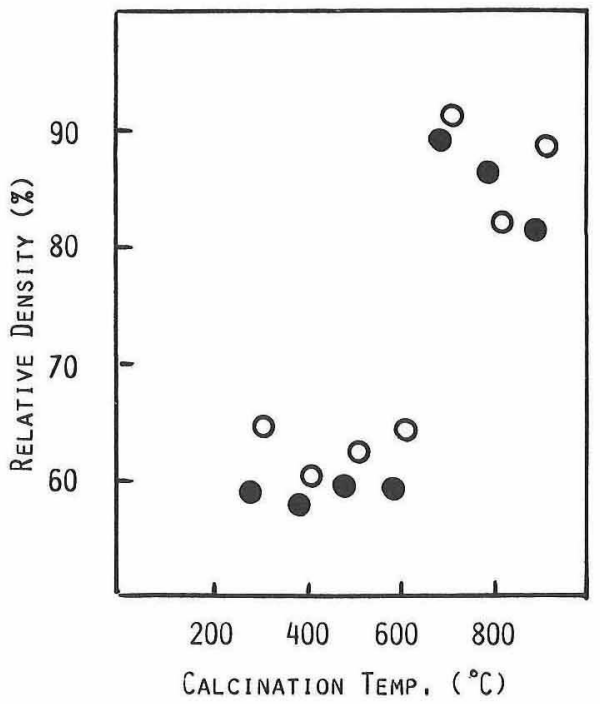

Fig.4. The effect of calcination temperature on the relative density of sintered $\beta$-tricalcium phosphate.

: Sintered in air at $1100^{\circ} \mathrm{C}, \bigcirc$ : Sintered under reduced pressure at $1100^{\circ} \mathrm{C}$

above $1000^{\circ} \mathrm{C}$ in order to obtain a single phase of $\beta$-TCP from ACP. However, since the transition of TCP into a high-temperature form was reported to occur at $1120^{\circ} \mathrm{C},{ }^{9}$ sintering temperature in most experiments was fixed at $1100^{\circ} \mathrm{C}$. Sintering processes were continued for $12 \mathrm{~h}$.

Figure 4 shows the effects of the calcination temperature of $\mathrm{ACP}$ on the relative density of sintered $\beta$-TCP.

The sintered bodies with relative density of $60-70 \%$ were obtained from the starting powders calcined at $300^{\circ}-660^{\circ} \mathrm{C}$ before sintering. Therefore, dehydrated and amorphous powders of ACP might be inadequate for preparation of dense $\beta$-TCP bodies. The relative density jumped and the sintered bodies of more than $90 \%$ of relative density were obtained from the starting powders calcined above $700^{\circ} \mathrm{C}$ and thermally crystallized. The density decreased slightly as the calcination temperature reached $800^{\circ} \mathrm{C}$. Probably, the sintering of the crystallized powder was to some extent restrained because of the grain growth of TCP. From the experimental results described above, the most appropriate powder for sintering was considered to be crystalline $\alpha$-TCP obtained at about $700^{\circ} \mathrm{C}$.

It was reported that, since crystallization of ACP began immediately after the complete dehydration, a very small quantity of residual water in ACP prevented the formation of TCP. ${ }^{11}$ Consequently, for the purpose of examining the effects of water on sintering the experimental results under reduced pressure were compared with those

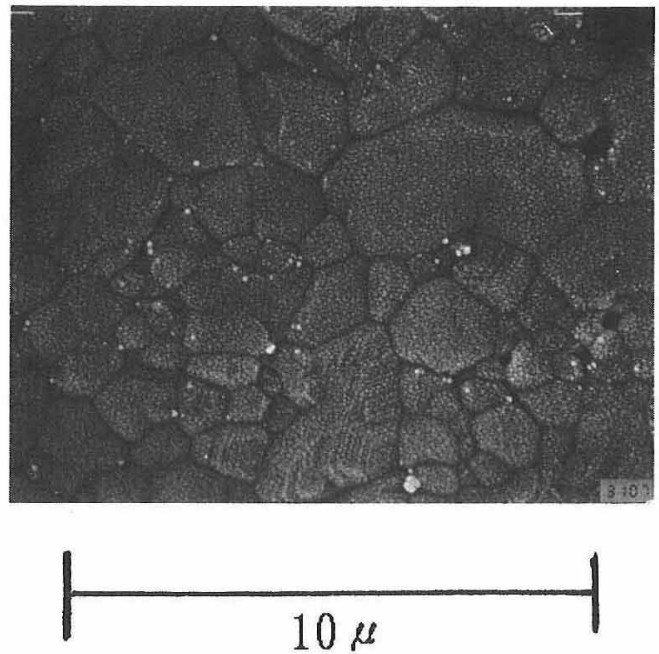

Fig.5. Scanning electron micrograph of the surface of sintered $\beta$-tricalcium phosphate.

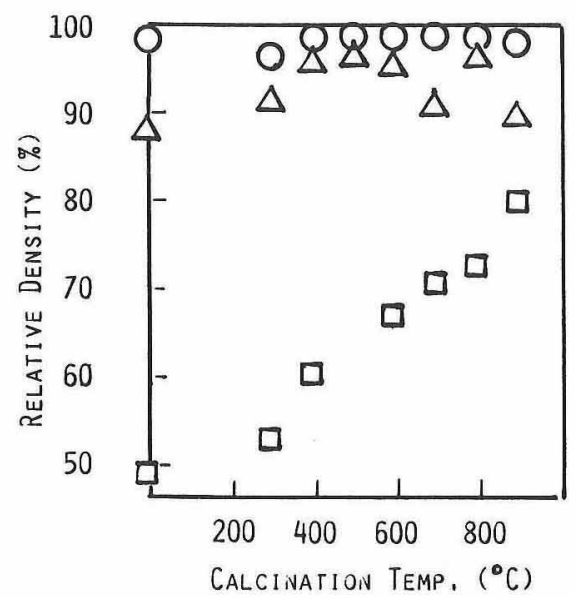

Fig.6. The effect of calcination temperature on the relative density of sintered $\beta$-tricalcium phosphate obtained by hot pressing.

$\square$ : Hot-pressed at $900^{\circ} \mathrm{C}, \triangle:$ Hot-pressed at $1000^{\circ} \mathrm{C}$, $\mathrm{O}$ : Hot-pressed at $1100^{\circ} \mathrm{C}$

in air. However, as Fig. 4 shows, there was almost no difference in the change of relative density between the two sintering methods.

Figure 5 shows the surface of sintered $\beta$-TCP from ACP calcined at $800^{\circ} \mathrm{C}$. Although small pores were observed, sintering might be completed.

The change in fired density on hot pressing are shown in Fig. 6. Sintering was carried out at 24 $\mathrm{MPa}$ for $30 \mathrm{~min}$ in a graphite die under reduced pressure. Above $1000^{\circ} \mathrm{C}, \beta$-TCP bodies with more than $90 \%$ of relative density were obtained. On hot pressing at $1100^{\circ} \mathrm{C}$, there was no dependency of relative density on calcination temperature. Slight pressing during sintering might 
remove the hindrance by mesopores in dehydrated ACP used as a starting powder.

From the results obtained so far, it was concluded that the elimination of mesopores was needed for the completion of sintering. There may be no relation between the sintering process of dehydrated ACP and the presence of residual water in ACP powders.

\section{Conclusion}

From the studies on sintering and powder properties concerning dehydrated ACP and crystallized TCP, the following findings were obtained.

(1) Pure $\alpha$-TCP was obtained from ACP, prepared by mixing the dilute solution of $\mathrm{Ca}^{2+}$ and phosphate (less than $0.2 \mathrm{~mol} / \mathrm{l})$ with high $\mathrm{pH}(\mathrm{pH}$ $=9-10)$.

(2) Dehydrated ACP powders possessed micropore and mesopore. Mesopore disappeared and micropore remained after thermal crystallization at $700^{\circ} \mathrm{C}$.

( 3 ) Sintered $\beta$-TCP with more than $90 \%$ of relative density was obtained from the powders calcined at $700^{\circ} \mathrm{C}$, while dense sintered bodies formed by hot pressing in case of the starting powders calcined at low temperature.

(4) The relative density change with cal- cination temperature under reduced pressure was very similar to that in air.

It was concluded that extinction of mesopore was more important than the removal of water in order to complete the sintering of dehydrated ACP powders.

Acknowledgement This work was in part supported by two Grants-in-Aid for Developmental Scientific Research (Nos. 57470052 and 61430018) from the Ministry of Education, Science and Culture (Japan).

\section{References}

1) T. Kanazawa, T. Umegaki and N. Uchiyama, J. Chem. Tech. Biotechnol., 32, 399-406 (1982).

2) T. Umegaki, S. Shiba and T. Kanazawa, Yogyo-KyokaiShi, 92, 612-16 (1984).

3) T. Kanazawa, T. Umegaki and N. Uchiyama, Nippon Kagaku Kaishi, 1981, 1664-68.

4) T. Umegaki, N. Yamashita and T. Kanazawa, Sekko to Sekkai, No.183, 11-15 (1983).

5) M. Jarcho, R.L. Salsbury, M. B. Thomas and R.H. Doremus, J. Mater. Sci., 14, 142-50 (1979).

6) L. W. Schroeder, B. Dickens and W. E. Brown, J. Solid State Chem., 22, 253-62 (1977).

7) B. C. Lippens and J.H. de Boer, J. Catal., 4, 319-23 (1965).

8) R.W. Cranston and F.A. Inkley, Adv. Catal., 9, 143-46 (1957).

9) W. Fix, H. Heymann and R. J. Heinke, J. Am. Ceram. Soc. , 52, 346-47 (1969). 